\title{
Factors Associated With Dropout, Retention and Graduation of Nursing Students in Selected Universities in South Africa: A Narrative Review
}

\author{
N. T. Nkutu ${ }^{1}$,E. Seekoe ${ }^{1} \&$ D.T. Goon ${ }^{1}$ \\ ${ }^{1}$ Faculty of Health Sciences, University of Fort Hare, East London, South Africa \\ Correspondence: N. T. Nkutu, Faculty of Health Sciences, East London, South Africa. E-mail: \\ nnkutu@ufh.ac.za
}

Received: August 7, 2018 Accepted: August 22, $2018 \quad$ Online Published: October 13, 2018

doi:10.5539/gjhs.v10n11p 80

URL: https://doi.org/10.5539/gjhs.v10n11p80

\begin{abstract}
Much has been discussed in workshops, meetings, seminars and nursing summits in South Africa but very little has been revealed in literature on the scourge of drop out, retention and graduation rates of nursing students. The authors reviewed literature related to dropout, retention, completion and graduation rates of nursing students in selected universities in South Africa. Journal articles from 2007-2016 were reviewed for emerging themes about nursing students' dropout, retention, completion, success and graduation. Exclusion criteria: online or distance education programmes, postgraduate programmes, experimental or randomized control trials and previous review studies. Comprehensive electronic search was conducted for published longitudinal and cross- sectional studies. Specific databases: PubMed, MEDLINE, EBSCO host, CINHAL. Specific search terms: ["student" OR "nursing"], OR ["dropout" OR, "retention"], OR ["graduation", OR "education" OR "success" OR "completion"] AND "universities" OR "undergraduate" AND ["strategies" OR "interventions"]. Thirty- four (34) studies met review criteria. Fifteen (15) (47.06\%) of the studies reported results on attrition, $16(47.06 \%)$ reported on retention and $3(8.82 \%)$ reported on completion and graduation. Academic, personal, preparedness and social factors were associated with dropout, retention and graduation of nursing students in South Africa. Dropout from undergraduate nursing programme is fraught with many problems. There is a need for retention models. Without nurses, much of the public health outcomes will be hardly achieved. If the problem of dropout and retention with decreased graduation persists, the health services will be crumbled thus affecting the realization of the health outcome "a long and healthy lifestyle for all".
\end{abstract}

Keywords: dropout/attrition, retention, graduation, undergraduate nursing student

\section{Introduction}

Whilst South Africa grapples with the quadruple burden of diseases on the health care system, there is a need for Nursing Education Institutions (NEIs) to pull up all the stops in producing quality, caring and safe nursing practitioners. However, there are serious concerns that need to be addressed by the NEIs, amongst which is a problem of dropout and retention strategies of nursing students in the undergraduate programmes. Figure 1 displays the production of nurses by the statutory body, the South African Nursing Council (SANC Statistics 2009-2011). 



\begin{tabular}{c|c|c|c|c|c|c|c|c|c|c|c|c|c|c|c|c|c|c|c|}
\hline & LIM & NW & MP & GP & FS & KZN & NC & WC & EC & & LIM & NW & MP & GP & FS & KZN & NC & WC & EC \\
\hline 009 & 80 & 10 & 0 & 108 & 51 & 70 & 0 & 225 & 127 & 2009 & 154 & 299 & 1 & 469 & 95 & 378 & 14 & 85 & 472 \\
\hline 010 & 81 & 18 & 0 & 127 & 47 & 69 & 0 & 168 & 119 & 2010 & 126 & 309 & 216 & 657 & 1135 & 486 & 62 & 101 & 245 \\
\hline 011 & 24 & 44 & 0 & 92 & 33 & 70 & 0 & 191 & 136 & 2011 & 224 & 190 & 140 & 571 & 141 & 500 & 56 & 110 & 444 \\
\hline
\end{tabular}

Figure 1. Production of nurses: 4-year programme at Universities and Public Nursing Colleges (SANC statistics) NB: Mpumalanga (MP) and Northern Cape (NC) have no universities

The production of nurses in the 4 year programmes at Universities and at Public Nursing Colleges in South Africa as displayed in figure 1 raises concerns. As from 2009 to 2011 a cursory examination of the production of undergraduate nurses as depicted by figure 1 from 2009 to 2011 raises a concern as to whether there is enough production of nurses to meet the goal of "A long and healthy lifestyle for all South Africans" as required by the South Africa's National Development Plan (2030); and whether the Human Resource for Health (HRH) Strategy by (2030) shall be realisable. These concerns are critical considering the dire shortage of nurses and the ever demanding workload of the nurses in providing quality care for the South African population. In South Africa the accredited NEIs are tasked with the mandate of producing nurses by the South African Nursing Council under regulation R425 of the Nursing Act (Act 33 of 2005).

Research regarding attrition and models for retention-to-graduation of nursing students in South African universities are very scanty, even though a lot has been done to assist the students towards graduation. Researchers have unanimously agreed that the disturbing shortage of nurses could be answered through effective retention and timeous graduation (Bowden, 2008; Crombie, Brindley, Harris, Marks-Maran \& Morris Thompson, 2013; Jeffreys, 2007b; Jeffreys, 2012). Despite the high students' annual enrolment into universities, only few graduate on time, while others delay or dropout (Roos, Fichardt, MacKenzie \& Raubenheimer, 2016). According to the National Development Plan (2030), a 25\% increase in enrolments is anticipated by 2030 and a $20 \%$ increased graduation rate is anticipated from now on (Department of Higher Education and Training's 2010/11-2014/15 Strategic Plan). It is a concern that only 48\% of students in residential universities graduate within 5 years whilst the country is in dire need of human resources for health now. Thus, the need to address retention and graduation rates will remain an issue of on-going debate and interest. As such, this paper sought to review literature uncovered in relation to dropout, retention and graduation rates of nursing students in the undergraduate programme in universities in South Africa in order to develop a retention-to-graduation model for undergraduate nursing students. The objectives of this paper was to review literature related to dropout, retention, completion and graduation rates of nursing students in universities from 2007-2016 in order to develop a retention-to-graduation model for undergraduate nursing programme.

\section{Methods}

This research used a narrative review in order to obtain studies eligible to be included in the research.

\subsection{Sample Inclusion / Exclusion Criteria}

Journal articles were reviewed and evaluated for emerging themes related to the factors associated with nursing student dropout, retention, success, completion and graduation rates worldwide with a view to identifying student characteristics, research strategies and interventions that prevent future student's departure from the undergraduate nursing programmes. In depth review of titles and abstracts to determine studies relevance for inclusion was conducted. Inclusion criteria was all the longitudinal or cross sectional studies that reported on nursing students on a full time basis in the undergraduate programme from 2007-2016, whether qualitative or quantitative studies. Exclusion criteria were all studies reporting on online or distance education programmes, those reporting on postgraduate programmes, experimental or randomized control trials and previous review 
studies.

\subsection{Search Strategy}

To identify studies dealing with factors associated with dropout, retention, success and graduation of nursing students in undergraduate programmes a comprehensive electronic search was conducted for longitudinal and cross sectional studies published between 2007 and 2016 in the following subject specific databases: PubMed, MEDLINE, EBSCO host, CINHAL. The specific search terms used were: ["student" OR "nursing"], OR ["dropout" OR, "retention"], OR ["graduation", OR "education" OR "success" OR "completion"] AND "universities" OR "undergraduate" AND ["strategies" OR "interventions"].The results of literature search are depicted in the flow diagram in Figure 2.

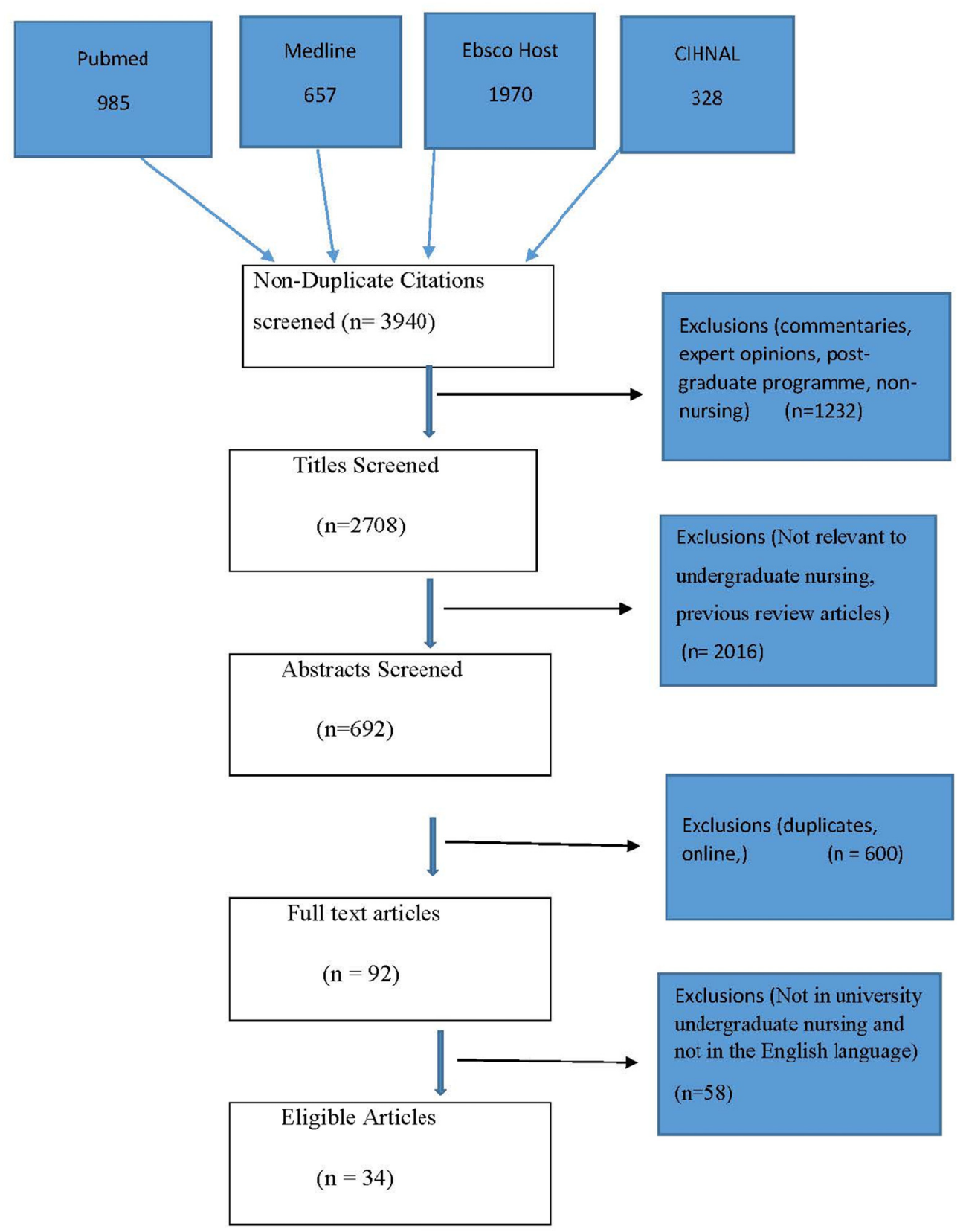

Figure 2. Showing the flow chart of search strategy results

\section{Results}

Thirty- four (34) studies met the criteria for review (Figure 2). The results present a number of factors globally associated with dropout, retention, and graduation rates of nursing students in the undergraduate nursing programme in universities. 
Table 1. Showing dropout, retention, completion and graduation studies $(n=34)$

\begin{tabular}{lll}
\hline Reviewed studies & Number & Percentage \\
\hline Dropout studies & 15 & 44.12 \\
Retention studies & 16 & 47.06 \\
Completion and Graduation & 3 & 8.82 \\
Total & 34 & 100 \\
\hline
\end{tabular}

Table 1 indicated that $15(44.12 \%)$ of the studies reviewed reported results on dropout, whilst $16(47.06 \%)$ of studies reported retention, and only $3(8.82 \%)$ studies on completion and graduation.

\subsection{Dropout Studies $(n=15)$}

Many researchers have alluded to the problem of dropout of nursing students in the undergraduate programme, (Andrew, Salamonson, Weaver, Smith, O’Reilly \& Taylor, 2008; Cameron, Roxburgh, Taylor \& Lauder, 2011; Crombie, Brindley, Harris, Marks-Maran \& Morris Thompson, 2013; Dapremont, 2011) citing several reasons ranging from involuntary (academic factors) to voluntary (personal factors). Previous studies have maintained that dropout rate is associated with academic and personal factors (Fowler \& Norrie, 2009; Jeffreys, 2007a; Letseka \& Maile, 2008; Levett-Jones, Lathlean, Higgins, \& McMillan, 2009).

\subsection{Involuntary (Academic Factors)}

Involuntary academic factors associated with dropout are academic difficulty coupled with lack of or inadequate support, under-preparedness, lack of commitment to the learning process, inappropriate study skills and habits, inadequate academic services, frequent absenteeism from class or clinical settings, lack of effective academic incorporation, financial constraints and language barrier (Andrew et al., 2008; Jeffreys, 2007b; Letseka \& Maile, 2008; Pryjmachuk, Easton \& Littlewood, 2008). On the other hand clinical placement with minimal support emerged as a factor in students leaving before graduation (Anonson, Desjarlais, Whiteman \& Bird, 2008).

\subsection{Voluntary (Personal Factors)}

\section{- Student profile characteristics}

Student characteristics like age, gender and ethnicity were also important predictors or actual factors of success or dropout in this literature review (Bosch, Doshier, Gess-Newsom, 2012; Cameron et al., 2011; Crombie et al., 2013; Dante, Petrucci \& Lancia, 2013; Eick, Williamson \& Heath, 2012; Fowler \& Norrie, 2009; HinsliffSmith, Gates \& Leducq, 2012; Jeffreys, 2012).

\section{- $\quad$ Student Affective factors}

Students' affective factors consist of the attitudes, values, and beliefs about education, nursing, and one`s ability to succeed. This includes cultural values and beliefs, self-efficacy, and motivation. Attitudes, values and beliefs of nursing students can be modified when they are mentored by experienced role-models who understand and have insight into the various techniques in student accompaniment especially into the clinical setting. Educators can also influence student' self-efficacy and motivation during their educational encounter (Jeffreys, 2012).

\subsection{Involuntary (First Semester Academic Dropout)}

The first year experience has shown the need for urgent interventions targeted at first year undergraduate nursing students on admission if dropout rate is to be reduced and increased retention and graduation rates achieved. Factors associated with involuntary first semester academic dropout were perceived lack of support; financial constraints; environmental factors and difficult transition and integration into the tertiary environment (Jeffreys, 2007b; Jeffreys, 2012; Letseka \& Maile, 2008; Tinto, 1993).

\subsection{Retention Studies $(n=16)$}

Sixteen (16) $40.07 \%$ of the studies found that mentorship programme tended to be facilitators of success for undergraduate nursing students. Researchers are of the opinion that a well- planned and well managed mentorship programme can reduce dropout and enhance retention, success and graduation of undergraduate nursing students. Besides mentorship programmes other factors pivotal between dropout and retention were support, academic preparedness and social (Baker, 2010; Nkutu \& Seekoe, 2013).

\subsection{Completion and Graduation Studies $(n=3)$}

Three (3) $8.8 \%$ of the studies reviewed reported students with higher entry qualifications and above $80 \%$ class and clinical attendance obtained better marks or were more likely to succeed in nursing programmes. Conversely, students with lower entry qualifications and who frequently absented themselves from class or 
clinical settings were more likely to have lower marks or drop out of the programme (Veal, Bull \& Miller, 2012; Williams, 2010).

\section{Discussion}

Literature revealed multidimensional factors related to dropout, retention and graduation of nursing students. Dropout trajectories were involuntary (academic), voluntary (personal reasons) and involuntary (first semester academic dropout). It is common to find first year nursing students quitting the undergraduate programme especially due to inadequate or lack of support and transition problems (Jeffreys, 2012).

Student profile characteristics have also emerged as factors in dropout, retention and graduation studies (Crombie et al., 2013; Eick et al., 2012; Fowler \& Norrie, 2009; Hinsliff-Smith et al., 2012: Jeffreys, 2007b; Jeffreys, 2012; Sutherland, Hamilton \& Goodman, 2007). However, maturity was seen as a predictor of success (Jeffreys, 2012). If a student has demonstrated good study habits and skills in prior educational programmes, and if they show up and get the necessary support, they would carry these skills to a new academic setting and attain their goals on time. The student affective factors also revealed that the belief patterns or system and values of students about education have an association with dropout, retention and graduation in undergraduate nursing programmes (Jeffreys, 2012). Future research should endeavour to examine the student affective factors and its association with dropout, retention and graduation in undergraduate nursing programmes, especially in the South African context.

\section{Conclusion}

The dropout, retention and graduation rates of undergraduate nursing programme in South African universities are fraught with a complexity of problems. There is a need for retention models. Retention-to-graduation models should be proposed to serve as recommendations. Without nurses, much of the public health outcomes will be hardly achieved (Savage \& Kub, 2009).

\section{Acknowledgements}

We thank the Govern Mbeki Research \& Development Council (GMRDC) for providing funding support of this research.

\section{Competing Interests Statement}

The authors declare that there are no competing or potential conflicts of interest.

\section{References}

Andrew, S., Salamonson, Y., Weaver, R., Smith, A., O'Reilly, R., \& Taylor, C. (2008). Hate the course or hate to go: semester differences in first year nursing attrition. Nurse Edu Today, 28, 865-872. https://doi.org/10.1016/j.nedt.2007.12.007

Anonson, J. M., Desjarlais, J., Whiteman, N. J. \& Bird, A. (2008). Strategies to support Recruitment and Retention of First Nations Youth in Baccalaureate Nursing Programs in Saskatchewan, Canada. $J$ Transcultural Nurs, 19(3), 274-283. https://doi.org/10.1177/1043659608317095

Baker, B. H. (2010). Faculty ratings of retention strategies for minority nursing students. Nur Edu Pers, 51(4), 216-220.

Bosch, P. C., Doshier, S. A., \& Gess-Newsom, J. (2012). Bilingual nurse education program: Applicant characteristics that predict success. Nurs Edu Res, 33(2), 90-95.

Bowden, J. (2008). Why do nursing students who consider leaving stay on their courses? Nurse Researcher, 15(3), 45-58. https://doi.org/10.7748/nr2008.04.15.3.45.c6456

Cameron, J., Roxburgh, M., Taylor, J., \& Lauder, W. (2011). An integrative literature review of student retention in programmes of nursing and midwifery education: why do students stay? J Clin Nurs., 1372-1382. https://doi.org/10.1111/j.1365-2702.2010.03336.x

Crombie, A., Brindley, J., Harris, D., Marks-Maran, D., \& Morris Thompson, T. (2013). Factors that enhance rates of completion: Why students stay? Nurse Edu Today, 33, 1282-1287. https://doi.org/10.1016/j.nedt.2013.03.020

Dante, A., Petrucci, C., \& Lancia, L. (2013). European nursing students' academic success or failure: A postBologna Declaration systematic review. Nurse Edu Today, 33, 46-52. https://doi.org/10.1016/j.nedt.2012.10.001

Dapremont, J. A. (2011). Success in nursing school: Black nursing students' perception of peers, family, and faculty. $J$ Nur Edu, 50, 254-260. https://doi.org/10.3928/01484834-20110317-03

Department of Higher Education and Training's 2010/11-2014/15 Strategic Plan. 
Eick, S. A., Williamson, G. R., \& Heath, V. (2012). A systemic review of placement-related attrition in nurse education. Int J Nur Studies; 49(10), 1299-1309. https://doi.org/10.1016/j.ijnurstu.2011.12.004

Fowler, J. \& Norrie, P. (2009). Development of an attrition risk prediction tool. Br J Nur, 18(19), 1194-1201. https://doi.org/10.12968/bjon.2009.18.19.44831

Global strategy on Human Resource for Health: Workforce 2030- Nursing \& Midwifery

Hinsliff-Smith, K., Gates, P., \& Leducq, M. (2012). Persistence, how do they do it? A case of access to higher education learners on a UK diploma/BSc nursing programme. Nursing Edu Today, 32, 27-31. https://doi.org/10.1016/j.nedt.2011.01.015

Jeffreys, M. R. (2007a). Non-traditional students' perceptions of variables influencing retention. Nurse Educator, 32(4), 161-167. https://doi.org/10.1097/01.NNE.0000281086.35464.ed

Jeffreys, M. R. (2007b). Tracking students through programme entry, progression, graduation, and licensure: Assessing undergraduate nursing student retention and success. Nurse Edu Today, 27, 406-419. https://doi.org/10.1016/j.nedt.2006.07.003

Jeffreys, M. R. (2012). Nursing Student Retention: Understanding the Process and Making a Difference (2nd Ed.). New York: Springer Publishing Company.

Letseka, M., \& Maile, S. (2008). High University drop-out rates: A threat to South Africa's future. Human Science Research Council; Pretoria.

Levett-Jones, T., Lathlean, J., Higgins, I., \& McMillan, M. (2009). Staff-student relationships and their impact on nursing students' belongingness and learning. J Adv Nurs, 65, 316-324. https://doi.org/10.1111/j.13652648.2008.04865.x

National Development Plan 2030: South African Government https://www.gov.za

Nkutu, N. T., \& Seekoe, E. (2013). Perceptions of undergraduate nursing students on peer mentorship training at University of Fort Hare, Eastern Cape, South Africa. Afr J Phy, Health Edu, Recre Dance October, (Suppl 1), 171-179.

Pryjmachuk, S., Easton, K., \& Littlewood, A. (2008). Nurse Education: factors associated with attrition. $J A d v$ Nurs., 65(1), 149-156. https://doi.org/10.1111/j.1365-2648.2008.04852.x

Roos, E., Fichardt, A. E., MacKenzie, M. J., \& Raubenheimer, J. (2016). Attrition of undergraduate nursing students at selected South African universities. Curationis, 39(1), a1558. http://dx.doi.org/10.4102/curationis.v39i1.155

Savage, C., \& Kub, J. (2009). Public Health and Nursing: A Natural Partnership. Int J Environ Res Public Health, 6(11), 2843-2848. https://doi.org/10.3390/ijerph6112843

South African Nursing Council Statistics 2009-2011. Pretoria.

Sutherland, J. A., Hamilton, M. J., \& Goodman, N. (2007). Affirming at-risk minorities for success (ARMS): retention, graduation and success on the NCLEX-RNTM. J Nurs Edu, 46, 347-353.

Veal, J. L., Bull, M. J., \& Miller, J. F. (2012). A Framework of academic persistence and success for ethnically diverse graduate nursing students. Nurs. Edu Res Perspectives, 33(5), 322-327. https://doi.org/10.5480/1536-5026-33.5.322

Williams, M. G. (2010). Attrition and retention in the nursing major: Undergraduate persistence in beginning nursing students. Nurs Edu Perspectives, 31(6), 362-367.

\section{Copyrights}

Copyright for this article is retained by the author(s), with first publication rights granted to the journal.

This is an open-access article distributed under the terms and conditions of the Creative Commons Attribution license (http://creativecommons.org/licenses/by/4.0/). 